\title{
Epic battles in endocrinology - malignant pheochromocytoma: a case report
}

\author{
Elżbieta Zych ${ }^{1}$, Aleksandra Jaruszewska', Łukasz Obołończyk ${ }^{2}$, Piotr Wiśniewski \\ Krzysztof Sworczak ${ }^{2}$, Katarzyna Chełmińska ${ }^{3}$, Jarosław Ćwikła ${ }^{4}$ \\ 'Endocrinological Students' Scientific Group, Medical University of Gdansk, Gdansk, Poland \\ ${ }^{2}$ Department of Endocrinology and Internal Medicine, Medical University of Gdansk, Gdansk, Poland \\ ${ }^{3}$ Independent Clinical Practice, Sopot, Poland \\ ${ }^{4}$ Department of Radiology, University of Warmia and Mazury, Olsztyn, Poland
}

\begin{abstract}
The rarity of malignant pheochromocytoma coupled with the lack of definitive predictors of malignancy and the variability of clinical course, poses a significant diagnostic and therapeutic challenge. Since data on treatment is so scarce, case reports are a valuable source of knowledge for clinicians.

This case report describes the medical history of a woman, aged 51 at the time of initial diagnosis and adrenalectomy. Within over 5 years she presented with recurrent relapse of tumour in adrenal gland bed and multiple distant metastases to descending colon, abdominal wall, postoperative scars, and the peritoneum. Neither before diagnosis nor during the whole follow-up were symptoms associated with pheochromocytoma present.

The treatment administered to our patient consisted of numerous debulking surgeries along with administration of both hot and cold somatostatin analogues. We believe that debulking surgeries played a substantial role in enabling the patient to survive nearly 6 years despite aggressive clinical course of pheochromocytoma. She passed away in 2012 as a result of postlaparotomy complications.

We stress the role of debulking surgery in the treatment of malignant pheochromocytoma and summarise current literature.
\end{abstract}

Key words: malignant pheochromocytoma; debulking surgery; case report; lanreotide

$$
\text { Arterial Hypertens. 2020, vol. 24, no. 1, pages: 38-43 }
$$

DOI: 10.5603/AH.a2020.0001

\section{Introduction}

Pheochromocytoma (pheo) is a rare catecholamine-secreting tumour, although it may also be nonfunctional [1]. Its prevalence is less than 5 per 1 million of the general population and less than $1 \%$ of the hypertensive population, with no significant gender predominance. Although in most cases benign, hormonally active pheo poses a real life threat due to the sympathetic system overstimulation. Malignant pheo constitutes $10-25 \%$ of all cases [2].
Given the rarity of this condition, therapeutic options are not well defined and those which are available are mostly palliative [3].

\section{Case report}

We present a case of a Caucasian female diagnosed with malignant pheo, treated with surgery along with both cold and hot somatostatin analogues. In October 2006, at the age of 51, she underwent an

Address for correspondence: Elżbieta Zych

Klinika Endokrynologii i Chorób Wewnętrznych, ul. Dębinki 7, 80-211 Gdańsk; tel: +48 5834928 41; e-mail: zych.elzbieta@gmail.com

VM Copyright (C) 2020 Via Medica, ISSN 2449-6170 


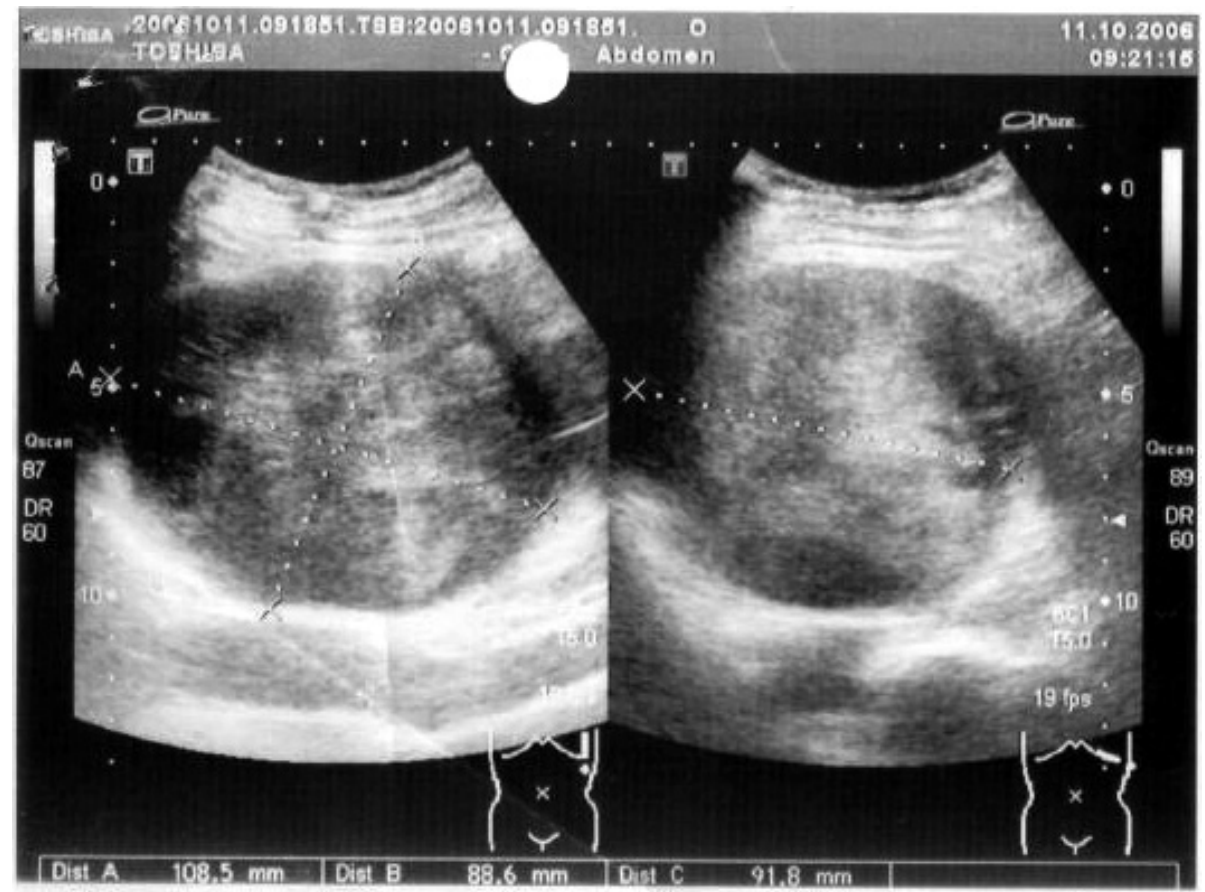

Figure 1. An ultrasound picture of a large $(109 \times 89 \times 92 \mathrm{~mm})$ adrenal tumour

abdominal ultrasound (US) scan due to recurring pains of the lumbar area. A $109 \times 89 \times 92 \mathrm{~mm}$ mass of the left adrenal gland was visualized. Irregular echogenicity and focal necrosis were described (Fig. 1). Typical pheo-associated symptoms, such as paroxysmal hypertension, tachycardia, sweating, tremors or anxiety were not present at any time. Multiple blood pressure readings in 2006 during a hospitalization ranged up to $120-130 / 80 \mathrm{~mm} \mathrm{Hg}$.

A computed tomography (CT) scan performed in October 2006 confirmed the presence of a $90 \times 95 \times 120 \mathrm{~mm}$ lesion in the left adrenal gland with focal necrosis and irregular attenuation coefficient along with moderate enhancement after contrast administration. The edges were well defined and the tumour did not involve the adjoining tissues (pictures not available). Laboratory testing showed normal function of the adrenal cortex and medulla. Total metanephrine level in a 24-h urine sample was $300 \mu \mathrm{g}$ (reference ranges $<1000 \mu \mathrm{g} / 24 \mathrm{~h}$ ). 24-h fractionated metanephrines were not assessed since such testing was unavailable at our centre at the time.

A classic adrenalectomy was performed in November 2006. The excised tumour measured $140 \times 120 \times 90 \mathrm{~mm}$ and weighed 430 grams. Pathologic evaluation indicated pheo with no invasion beyond the capsule. Immunohistochemical staining was positive for chromogranin A and synaptophysin.

A CT scan performed in January 2007 showed no signs of recurrence; however, shortly after that the patient reported two tumours she palpated in the scar. In US two solid lesions in subcutaneous tissue were described. In March 2007 the nodules were excised and the histopathological examination indicated pheo. Diagnosis of malignant pheo was suspected. Bone scintigraphy performed in February 2008 revealed no pathological uptake. A routine, follow-up CT scan the patient underwent in May 2008. Examination revealed a $25 \times 29 \times 36 \mathrm{~mm}$ mass in the left adrenal gland bed together with 2 tumours in the scar area and descending colon wall thickening with considerable narrowing. Hormonal evaluation revealed no catecholamine excess again. Genetic testing for RET, $V H L, N F 1, S D H B, S D H C$ and $S D H D$ mutations was negative.

Because of those findings our patient underwent a laparotomy in June 2008, when a left hemicolectomy was performed and the abdominal wall tumours were removed. The mass in the left adrenal bed was deemed inoperable due to infiltration of both superior mesenteric vein and left renal vessels.

At that time, the diagnosis was unclear. The clinical picture could indicate both pheo-paraganglioma syndrome and malignant pheo due to the fact that the masses appeared in the area that was previously operated on. However, malignant pheo was highly suspected. In order to investigate the therapeutic options the patient underwent a ${ }^{123} \mathrm{I}$-MIBI scintigraphy along with ${ }^{99 \mathrm{~m}} \mathrm{HYNIC}$ TOC and NeoSPECT ${ }^{99 \mathrm{~m}}$ Tc-HYNIC-TOC scans, the results of which in- 


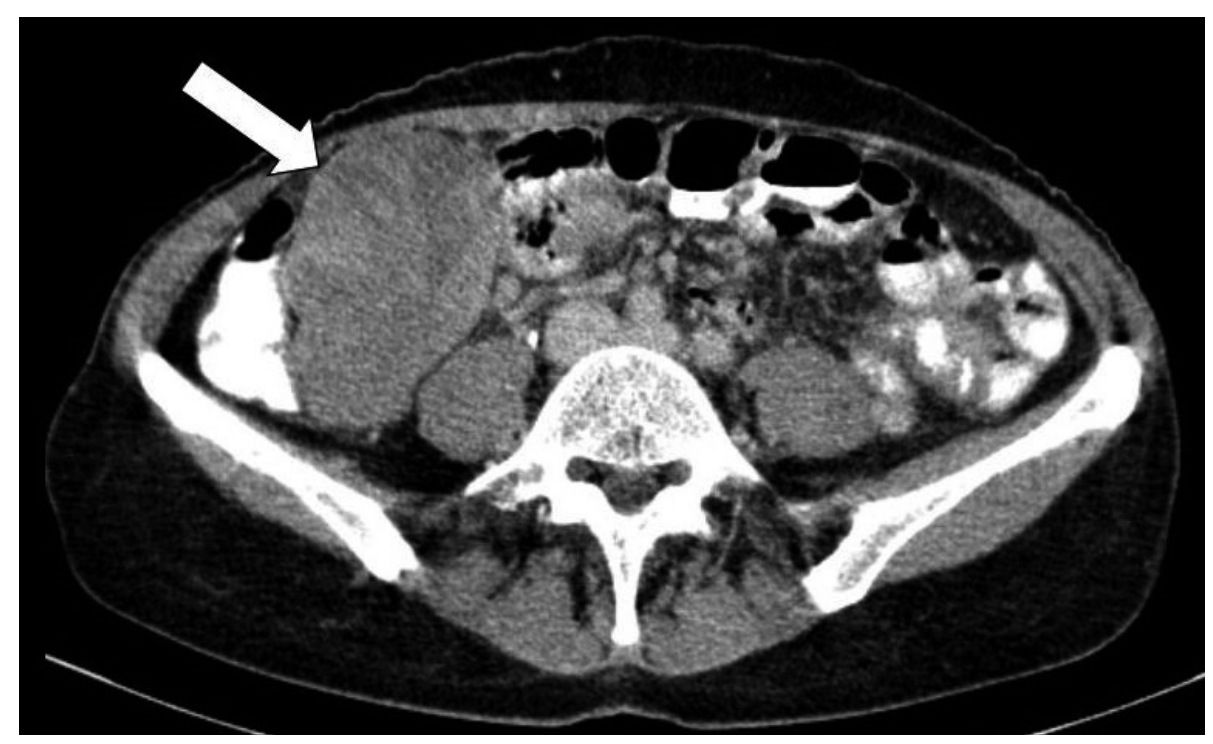

Figure 2. A CT scan of a large pathological mass $(10 \times 9 \times 6 \mathrm{~cm})$ in the right mid abdomen

dicated that somatostatin analogues would be the best option, with lanreotide as a first choice. ${ }^{123} \mathrm{I}$ MIBI was decided against due to insufficient tracer uptake.

In September 2008 the patient presented with abdominal pain and underwent a CT scan. A large mass $10 \times 9 \times 6 \mathrm{~cm}$ in the right mid abdomen was revealed and a month later it was excised. Histopathologically, pheo was described and final diagnosis of malignant pheo was established (Fig. 2).

Follow-up CT (December 2008) revealed two pathological masses in primary tumour bed. The larger one was $42 \times 14 \mathrm{~mm}$ and the smaller one was $19 \times 12 \mathrm{~mm}$. Radiolabelled lanreotide (Y90-Lan) was administered in November 2008 and January 2009. In February 2009 the patient underwent a surgical excision of a new pathological mass in the skin of left anterior superior iliac spine area.

A month later she presented with pancytopenia which caused the diagnosis of multiple myeloma to be considered. Full diagnostic workup was performed and multiple myeloma was excluded. Pancytopenia was attributed to hot somatostatin analogue treatment, which was therefore discontinued. Because of abdominal pain, another abdominal CT was performed. Examination revealed progression of previously described tumours and new pathological mass in pelvis (left ovary area) measuring $38 \times 31$ $\mathrm{mm}$ (CT scans not available).

In June 2009, after a consultation we decided on debulking surgery. Extensive procedure with tumour in left adrenal bed resection (in June 2008 described as nonoperative), left nephrectomy and anterio-superior rectal resection and partial small bowel resection was performed. Histopathologically, every resected tumour contained pheo tissue.

Routine abdominal US revealed new pathological masses in skin and subcutaneous tissue. In May and September 2010 our patient underwent two surgical procedures. First, lesions in the abdominal wall were excised, and the second operation involved the removal of 2 retroperitoneal tumours. "Cold analogue" lanreotide therapy was started in September 2010 and was continued throughout the whole follow-up period.

In February 2011 a positron emission tomography (PET) scan showed high risk of peritonitis carcinomatosa and therefore, in April 2011, a laparotomy was performed. At the time an intramural tumour of the rectum was removed together with 26 tumours from the retroperitoneum.

In June 2011 pathological masses behind the front abdominal wall were discovered. No surgical procedure was performed. In March 2012 the patient presented with nausea, abdominal pain together with rapid increase in creatinine levels and oliguria, which led to the diagnosis of hydronephrosis. A double J stent was placed in the right ureter which alleviated the patient's symptoms. A CT scan performed at that time revealed further disease progression with large tumour in primary tumour bed $(85 \times 65 \times 100 \mathrm{~mm})$, few peritoneal implants and new $17 \mathrm{~mm}$ pathological mass in pelvis compressing right ureter. The patient underwent a laparotomy. The perioperative period was complicated with a severe haemorrhage, which was fatal. Prior to the last laparotomy the patient was offered treatment with chemotherapy, which she declined. She had 
Table 1. History of pheochromocytoma management

\begin{tabular}{|c|c|}
\hline \multicolumn{2}{|c|}{ History of pheochromocytoma management (precise dates in text) } \\
\hline 2006 & $\begin{array}{l}\text { Ultrasound - } 108 \times 88 \times 92 \mathrm{~mm} \text { tumour of left adrenal gland } \\
\text { Abdominal CT }-90 \times 95 \times 120 \text { mass of the left adrenal gland (focal necrosis, irregular attenuation coefficient, moderate enhance- } \\
\text { ment after contrast administration, no involvement of adjoining structures) } \\
\text { 24-hour urine metoxycatocholamine levels }-300 \mu \mathrm{g} \\
\text { Classic left adrenalectomy (tumour } 140 \times 120 \times 90 \mathrm{~mm}, 430 \mathrm{~g} \text { ); histopathologically-confirmed pheo }\end{array}$ \\
\hline 2007 & $\begin{array}{l}\text { CT clear of any lesions in both adrenal areas } \\
\text { Later } 2 \text { tumours in postoperative scar }- \text { on ultrasound } 1.48 \times 1.43 \mathrm{~cm} \text { and } 2.09 \times 1.27 \mathrm{~cm} \text {; histopathologically-confirmed pheo }\end{array}$ \\
\hline 2008 & $\begin{array}{l}\text { Bone scintigraphy shows no pathological tracer accumulation } \\
2^{\text {nd }} \text { surgery - tumours in the scar excised histopathologically-confirmed pheo } \\
\text { Abdominal CT }-25 \times 29 \times 36 \mathrm{~mm} \text { mass in the left adrenal bed, } 2 \text { tumours in the abdominal wall, descending colon wall } \\
\text { thickening with considerable luminal narrowing } \\
3^{\text {rd }} \text { surgery - left hemicolectomy, abdominal wall tumours excised, mass in the left adrenal bed considered inoperable; } \\
\text { histopathologically-confirmed pheo } \\
\text { Abdominal CT - right mid abdomen tumour, } 2 \text { abdominal wall tumours } \\
4^{\text {th }} \text { surgery - whole pathological mid abdominal mass excised, tumours in the abdominal wall considered inoperable } \\
\text { histopathologically-confirmed pheo } \\
1^{\text {st }} \text { dose of Y-90-Lanreotide }(1.15 \mathrm{GBq})\end{array}$ \\
\hline 2009 & $\begin{array}{l}2^{\text {nd }} \text { dose of Y-90-Lanreotide }(1.2 \mathrm{GBq}) \\
5^{\text {th }} \text { surgery - nodule in the left anterior superior iliac spine area excised; histopathologically-confirmed pheo } \\
\text { Pancytopenia attributed to hot somatostatin analogues treatment } \\
6^{\text {th }} \text { surgery - left nephrectomy, tumour previously considered inoperable resected, anterio-superior rectal resection, } \\
\text { partial small bowel resection; histopathologically-confirmed pheo in each localization }\end{array}$ \\
\hline 2010 & $\begin{array}{l}7^{\text {th }} \text { surgery }- \text { abdominal wall tumour excised histopathologically-confirmed pheo } \\
8^{\text {th }} \text { surgery }- \text { abdominal wall tumour and } 2 \text { retroperitoneal lesions excised; histopathologically-confirmed pheo } \\
\text { Long-acting lanreotide therapy initiation }\end{array}$ \\
\hline 2011 & $\begin{array}{l}\text { FDG-PET scan — high risk of peritonitis carcinomatosa, confirmed in a CT scan } \\
9^{\text {th }} \text { surgery — intramural tumour of the rectum and } 26 \text { retroperitoneal implants resected }\end{array}$ \\
\hline 2012 & $\begin{array}{l}\text { Double } \mathrm{J} \text { stent placed in the right ureter (obstructive hydronephrosis) } \\
\mathrm{CT}-\text { further disease progression } \\
10^{\text {th }} \text { laparotomy - severe haemorrhage turns out to be fatal }\end{array}$ \\
\hline
\end{tabular}

CT — computed tomography; pheo — pheochromocytoma; Y-90-Lanreotide — yttrium-90-labelled lanreotide; GBq — gigabecquerel; FDG-PET scan — fluorodeoxyglucose positron emission tomography

never had typical symptoms of pheo. All procedures are summarized in Table 1.

\section{Discussion}

Due to rarity and variability of clinical presentation, pheo is a real diagnostic challenge for physicians [2]. The clinical course may be highly variable and no definitive predictive factors of malignancy are currently available. Recent data shows that tumours with $S D H B$ mutation present significantly higher rates of malignancy [4]. Owing to the fact that a remarkable number of patients still die due to hormone overproduction, the main treatment objectives are controlling the tumour mass and hormonal symptoms [3]. Pheo is considered a secondary cause of hypertension, one that can be corrected surgically. Therefore it needs to be taken into account in every patient presenting with an adrenal tumour together with hypertension (paroxysmal or persistent). Even in the absence of typical symptoms and elevation of biochemical markers one cannot exclude pheo (malignant or benign) [5].

The diagnosis of malignancy can only be made by the discovery of distant metastases, direct invasion of surrounding tissues or presence of pheo in sites where chromaffin tissue is normally absent [6]. Pathologic markers are not predictive enough to be considered reliable in terms of tumour malignancy $[2,3]$. Most common metastatic sites include liver, lungs, lymph nodes and bones [7]. Metastases may appear as long as 20 years after initial presentation, therefore long-term follow-up is mandatory [8].

Data concerning survival rates varies - some patients present a more aggressive clinical course and die within 5 years of the diagnosis, whereas others show no disease progression for many years despite not receiving any targeted therapy [2]. In the literature we reviewed, survival times ranged from 1 year to 23 years $[2,9]$. However, since there are no reliable prognostic factors, determining the aggressiveness of the clinical course is impossible. 
Therefore a dilemma naturally arises — whether to treat and when to treat.

Given the rarity of malignant pheo, there definitely is a lack of prospective and randomized studies. Available data is not completely reliable as reports on efficacy of different treatment modalities are variable. Having analysed a number of reports, we feel that the following findings are worth mentioning.

Chemotherapy seems to bring the most benefit to patients presenting with rapidly progressive disease rather than those with a more indolent clinical course [3], although Tanabe et al. found it to be more effective in the latter group [10].The use of CVD (cyclophosphamide, vincristine, dacarbazine) regimen is well-recognized. Its implementation was justified by the resemblance between chromaffin tumours and neuroblastomas [11]. Adverse effects are mostly mild, the most common being gastrointestinal symptoms, leukopenia and hepatic dysfunction. If there is no significant response (biochemical or tumoural) after 4-5 cycles of CVD, it should be discontinued [10]. For inoperable lesions or multiple hepatic metastases, transcatheter arterial embolization with concomitant administration of doxorubicin or mitomycin- $C$ has been attempted $[12,13]$.

In the case of malignant pheo surgery should be considered as a treatment of choice for both primary tumours and metastases [14]. Its intent may be to cure the disease or alleviate hormonal as well as compression-related symptoms [15]. Moreover, debulking surgery may also improve response to later treatment $[8,15]$. Prior to surgery, as for every other treatment in the case of a hormonally active disease, adequate alpha-adrenergic blockade is mandatory $[16,17]$. This prevents intraoperative complications related to massive catecholamine release, such as a hypertensive crisis, arrhythmias and myocardial infarction. Although surgical resection is the only potentially curative approach, it is rarely feasible due to delayed diagnosis of malignancy. In some cases metastasectomy proved to be a sufficient treatment, leading to complete remission and patients remaining asymptomatic for years $[18,19]$. Our patient underwent multiple debulking surgeries which, together with long-term lanreotide treatment, enabled the almost six-year follow-up that she achieved. Reducing tumour burden might have facilitated better outcome of lanreotide therapy since cold somatostatin analogues alone have not shown considerable efficacy in treatment of malignant pheo.

Approximately $36 \%$ of patients diagnosed with malignant pheo are carriers of a hereditary germline mutation of $S D H B$ (succinate dehydrogenase sub- unit B) [20]. Malignant pheos, particularly those associated with $S H D B$ mutation, have been reported to be highly vascularized tumours. Therefore, antiangiogenic therapy with sunitinib was implemented. Although not curative, it can be an alternative for patients with progressive disease resistant to therapy or not eligible for other treatment modalities [20]. The effectiveness seems to be satisfying, as sunitinib was reported to lead to at least disease stabilization. Shen et al. described necrosis of majority of the metastatic masses as a result of this course of treatment [21]. Side effects included hypothyroidism, hypertension and haematological toxicity $[9,21,22]$.

${ }^{123}$ I-MIBG treatment has been attempted in various dose settings. According to Rose et al., repeated high-dose ${ }^{131}$ MIBG may be associated with long-term survival [23]. Single high-dose administration was also proven effective. However, this kind of treatment may result in a high percentage of severe haematological toxicity. Multiple intermediate or low doses regimens were more tolerable and had a reduced rate of myelosuppression while still offering a chance of prolonged survival [24-27]. Even in the case of "non-responders" in terms of tumour shrinkage or biochemical parameters, this course of therapy brought considerable symptomatic relief, therefore improving the patients' quality of life. In order to prevent hypothyroidism, thyroid blockade should be attempted even though it has been reported that despite potassium iodate use, tracer uptake to the thyroid is still visible on the scans [25].

If the lesions show sufficient tracer uptake on somatostatin receptor scintigraphy, treatment with somatostatin analogues may be attempted [27]. Generally, radioactive analogues are recommended, as "cold" ones have resulted in only transient responses. Lamarre-Cliche et al. proved that slow-release octreotide administered in the group of patients who did not undergo debulking surgery or receive other treatment such as MIBG or embolization appears to not be of sufficient effectiveness for the long-term treatment [28]. Moreover, it does not improve pheo-related symptoms significantly. Side effects of radioactive SST analogues are mainly haematological, as shown in the case of our patient, who became pancytopenic due to treatment with a hot SST analogue and had to be treated with non-labelled lanreotide instead.

\section{Conclusion}

The rarity of malignant pheochromocytoma, lack of definitive predictors of malignancy and the vari- 
ability of clinical course pose a significant diagnostic and therapeutic challenge. Since data on treatment is so scarce, case reports are a valuable source of knowledge for clinicians.

Debulking surgery may play a substantial role in prolonging the patients' survival.

\section{References}

1. Lenders JWM, Duh QY, Eisenhofer G, et al. Endocrine Society. Pheochromocytoma and paraganglioma: an endocrine society clinical practice guideline. J Clin Endocrinol Metab. 2014; 99(6): 1915-1942, doi: 10.1210/jc.2014-1498, indexed in Pubmed: 24893135.

2. Wan WH, Tan KY, Ng C, et al. Metastatic malignant phaeochromocytoma: A rare entity that underlies a therapeutic quandary. Asian J Surg. 2006; 29(4): 294-302, doi: 10.1016/ S1015-9584(09)60106-8, indexed in Pubmed: 17098666.

3. Baudin E, Habra MA, Deschamps F, et al. Therapy of endocrine disease: treatment of malignant pheochromocytoma and paraganglioma. Eur J Endocrinol. 2014; 171(3): R111-R122, doi: 10.1530/EJE-14-0113, indexed in Pubmed: 24891137.

4. Giubellino A, Sourbier C, Lee MJ, et al. Targeting heat shock protein 90 for the treatment of malignant pheochromocytoma. PLoS One. 2013; 8(2): e56083, doi: 10.1371/journal.pone.0056083, indexed in Pubmed: 23457505.

5. Sołtysiak M, Gołofit P, Łokaj M, et al. Biochemically silent pheochromocytoma - rare, but not uncommon. Case study. Art Hyperten. 2015; 19(4): 200-202, doi: 10.5603/ah.2015.0025.

6. Januszewicz W, Jarząb B, Januszewicz A, et al. Malignant pheochromocytoma. Nadciśnienie Tętnicze. 2005; 9(2): 132-140.

7. Yu J, Pacak K. Management of Malignant Pheochromocytoma. The Endocrinologist. 2002; 12(4): 291-299, doi: 10.1097/00019616-200207000-00007.

8. Adjallé R, Plouin PF, Pacak K, et al. Treatment of malignant pheochromocytoma. Horm Metab Res. 2009; 41(9): 687-696, doi: 10.1055/s-0029-1231025, indexed in Pubmed: 19672813.

9. Zukauskaite R, Hjorthgau K, Poulsen PL, et al. Malignant pheochromocytoma and paraganglioma: three cases illustrating the use of molecular targeted diagnostics and therapy and possible role of new drugs. Acta Oncol. 2011; 50(8): 1255-1259, doi: 10.3 109/0284186X.2011.584552, indexed in Pubmed: 21714698.

10. Tanabe A, Naruse M, Nomura K, et al. Combination chemotherapy with cyclophosphamide, vincristine, and dacarbazine in patients with malignant pheochromocytoma and paraganglioma. Horm Cancer. 2013; 4(2): 103-110, doi: 10.1007/s12672-0130133-2, indexed in Pubmed: 23361939.

11. Huang H, Abraham J, Hung E, et al. Treatment of malignant pheochromocytoma/paraganglioma with cyclophosphamide, vincristine, and dacarbazine: recommendation from a 22-year follow-up of 18 patients. Cancer. 2008; 113(8): 2020-2028, doi: 10.1002/cncr.23812, indexed in Pubmed: 18780317.

12. Watanabe D, Tanabe A, Naruse M, et al. Transcatheter arterial embolization for the treatment of liver metastases in a patient with malignant pheochromocytoma. Endocr J. 2006; 53(1): 59-66, doi: 10.1507/endocrj.53.59, indexed in Pubmed: 16543673.

13. Kim JK, Kim BH, Baek SM, et al. Incidentally detected inoperable malignant pheochromocytoma with hepatic metastasis treated by transcatheter arterial chemoembolization. Endocrinol Metab (Seoul). 2014; 29(4): 584-589, doi: 10.3803/ EnM.2014.29.4.584, indexed in Pubmed: 25325276.
14. Edström Elder E, Hjelm Skog AL, Höög A, et al. The management of benign and malignant pheochromocytoma and abdominal paraganglioma. Eur J Surg Oncol. 2003; 29(3): 278-283, doi: 10.1053/ejso.2002.1413, indexed in Pubmed: 12657240.

15. Jimenez C, Rohren E, Habra MA, et al. Current and future treatments for malignant pheochromocytoma and sympathetic paraganglioma. Curr Oncol Rep. 2013; 15(4): 356-371, doi: 10.1007/ s11912-013-0320-x, indexed in Pubmed: 23674235.

16. Babinska A, Peksa R, Sworczak K. Primary malignant lymphoma combined with clinically "silent" pheochromocytoma in the same adrenal gland. World J Surg Oncol. 2015; 13: 289, doi: 10.1186/ s12957-015-0711-6, indexed in Pubmed: 26419235.

17. Januszewicz W, Prejbisz A, Januszewicz A, et al. Pheochromocytoma - Disease that Can Stimulate Many Different Syndromes. Nadciśnienie Tętnicze. 2002; 6(3): 217 -228.

18. López-Gómez J, Salazar-Álvarez MaA, Adame RY, et al. Metastatic pheochromocytoma to liver without elevation of metanephrines and catecholamines. Int J Surg Case Rep. 2016; 29: 71-75, doi: 10.1016/j.ijscr.2016.10.050, indexed in Pubmed: 27821293.

19. Arnas-Leon C, Sánchez V, Santana Suárez AD, et al. Complete Remission in Metastatic Pheochromocytoma Treated with Extensive Surgery. Cureus. 2016; 8(1): e447, doi: 10.7759/cureus.447, indexed in Pubmed: 26918215.

20. Favier J, Igaz P, Burnichon N, et al. Rationale for anti-angiogenic therapy in pheochromocytoma and paraganglioma. Endocr Pathol. 2012; 23(1): 34-42, doi: 10.1007/s12022-011-9189-0, indexed in Pubmed: 22183643.

21. Sun FK, He HC, Su TW, et al. Multi-targeted tyrosine kinase inhibitor sunitinib: a novel strategy for sporadic malignant pheochromocytoma. Chin Med J (Engl). 2012; 125(12): 2231-2234, indexed in Pubmed: 22884159.

22. Hata J, Haga N, Ishibashi K, et al. Sunitinib for refractory malignant pheochromocytoma: two case reports. Int Urol Nephrol. 2014; 46(7): 1309-1312, doi: 10.1007/s11255-014-0663-8, indexed in Pubmed: 24510251.

23. Rose B, Matthay KK, Price D, et al. High-dose 131I-metaiodobenzylguanidine therapy for 12 patients with malignant pheochromocytoma. Cancer. 2003; 98(2): 239-248, doi: 10.1002/ cncr.11518, indexed in Pubmed: 12872341.

24. Rutherford MA, Rankin AJ, Yates TM, et al. Management of metastatic phaeochromocytoma and paraganglioma: use of iodine-131-meta-iodobenzylguanidine therapy in a tertiary referral centre. QJM. 2015; 108(5): 361-368, doi: 10.1093/qjmed/ hcu208, indexed in Pubmed: 25267727.

25. Lam MG, Lips CJM, Jager PL, et al. Repeated [131I]metaiodobenzylguanidine therapy in two patients with malignant pheochromocytoma. J Clin Endocrinol Metab. 2005; 90(10): 5888-5895, doi: 10.1210/jc.2004-2290, indexed in Pubmed: 16046591.

26. Gedik GK, Hoefnagel CA, Bais E, et al. 131I-MIBG therapy in metastatic phaeochromocytoma and paraganglioma. Eur J Nucl Med Mol Imaging. 2008; 35(4): 725-733, doi: 10.1007/s00259007-0652-6, indexed in Pubmed: 18071700.

27. Chrisoulidou A, Kaltsas G, Ilias I, et al. The diagnosis and management of malignant phaeochromocytoma and paraganglioma. Endocr Relat Cancer. 2007; 14(3): 569-585, doi: $10.1677 /$ ERC-07-0074, indexed in Pubmed: 17914089.

28. Lamarre-Cliche M, Gimenez-Roqueplo AP, Billaud E, et al. Effects of slow-release octreotide on urinary metanephrine excretion and plasma chromogranin A and catecholamine levels in patients with malignant or recurrent phaeochromocytoma. Clin Endocrinol (Oxf). 2002; 57(5): 629-634, doi: 10.1046/j.13652265.2002.01658.x, indexed in Pubmed: 12390337. 